\title{
SOLAR ULTRAVIOLET ATTENUATION DURING THE AUSTRALIAN (RED DAWN) DUST EVENT OF 23 SEPTEMBER 2009
}

by Nathan Downs, Harry Butler, and Alfio Parisi

Measurements of spectral ultraviolet attenuation are presented for a severe dust event in Australia.

T he transport of total column dust loads over central and eastern Australia during the extreme dust storm event of 23 September 2009 has stimulated several research studies. These studies have characterized the aerosol distribution and density, considered the spatial deposition of particulate matter, and evaluated the local economic impact (Jones and Christopher 2011; Jayaratne et al. 2011;

AfFiliations: Downs, Butler, AND PARISI-International Centre for Applied Climate Sciences, University of Southern Queensland, Toowoomba, Queensland, Australia CORRESPONDING AUTHOR: Nathan Downs, International Centre for Applied Climate Sciences, University of Southern Queensland, West Street, Toowoomba 4350 QLD, Australia E-mail: downsn@usq.edu.au

The abstract for this article can be found in this issue, following the table of contents. DOI:I0.II75/BAMS-D-I5-00053.I

A supplement to this article is available online (10.1175/BAMS-D-15-00053.2)

In final form 14 April 2016

(C2016 American Meteorological Society
Leys et al. 2011; Gabric et al. 2015; McGowan and Soderholm 2012; Tozer and Leys 2013). The storm, named Red Dawn by the national media, affected over $3,000 \mathrm{~km}$ of the east Australian coast. The major population centers of Sydney $\left(33.9^{\circ} \mathrm{S}, 150.6^{\circ} \mathrm{E}\right)$ and Brisbane $\left(27.5^{\circ} \mathrm{S}, 153.0^{\circ} \mathrm{E}\right)$ were blanketed with a thick reddish haze that reduced visibility to less than $1 \mathrm{~km}$ (Leys et al. 2011). The UV index did not exceed 3 during the passage of the storm in either city (Australian Radiation and Nuclear Safety Authority 2015). Maximum hourly particulate concentrations exceeding $15,000 \mu \mathrm{g} \mathrm{m}^{-3}$ (Leys et al. 2011) have elevated the September 2009 event to the most significant in recent history, eclipsing the dust event of 23 October 2002 (Chan et al. 2005; McTainsh et al. 2005).

Several studies have considered ultraviolet (UV, 290-400 $\mathrm{nm}$ ) attenuation by mineral aerosols from extreme Saharan and Chinese dust events; several of these events affected air quality in the United States (Prospero 1999; Husar et al. 2001; VanCuren and Cahill 2002). Significant Saharan dust events affecting the Mediterranean and Spain have been reported by Román et al. (2013), Antón 
et al. (2012), and di Sarra et al. (2002). The Saharan UV attenuation dust studies, conducted during the period May-September, are characterized by the predominant North African high pressure at altitude (NAH-A) synoptic conditions (Toledano et al. 2007; Escudero et al. 2005). The NAH-A conditions are associated with strong low pressure convection, capable of lifting dust to very high altitudes (Toledano et al. 2007; Meloni et al. 2004). This is typical of Saharan dust events, which retain the warm, dry, and stable air characteristics of their source during transport (Dunion and Velden 2004). The NAH-A and use of sun photometers to determine aerosol properties (under cloud-free conditions) allow the attenuation of dust aerosol to be studied exclusively. Under these cloud-free conditions, the Saharan studies report reductions up to threshold wavelengths in the UV spectrum of between $20 \%$ and $60 \%$ relative to clearsky conditions for solar zenith angles (SZAs) ranging from $20^{\circ}$ to $60^{\circ}$. The Saharan studies exemplify strong attenuation across the UV spectrum. These attenuations decrease with increasing wavelength after $315 \mathrm{~nm}$ for aerosol optical depths (AODs) between 0.5 and 1.76 .

Broadband radiometric attenuation of surface UV due to the presence of dust aerosols over northern China were recently reported by Jin et al. (2014) and are the first available UV attenuation data for this region. A point of difference between the study of Jin et al. (2014) and the Saharan UV attenuation studies is that Jin et al. (2014) considered the seasonal influence of dust aerosols over the 5-yr period of 2007-11. Their analysis considered the attenuation of the surface UV radiation due to dust-, cloud-, and dust-plus-cloud-affected days. The greatest reduction in the UV occurred under the combined influence of dust-plus-cloud conditions. Jin et al. (2014) concluded dust aerosol was the main contributing factor to the observed UV attenuation, being 2-4 times greater than attenuation caused by cloud coverage. The seasonal study of Jin et al. (2014) reported a maximum reduction in the total daily UV radiation due to desert sand particles and cloud cover of $83.3 \%$. This reduction was associated with the approach of a cold front (Yin et al. 2013) and is the largest reported attenuation of the surface UV irradiance during a severe dust event.

The possibility that cloud cover may compound the potential UV attenuation during severe dust events is significant, particularly within the Australian context in which the easterly passage of dust storms is frequently associated with cold fronts and prefrontal troughs that approach ahead of strong frontal westerly winds and high-tropospheric dust loads (Strong et al. 2011). An analysis of the UV transmission for cloud types and cloud fraction made over two years by Kuchinke and Nunez (1999) has shown the median attenuation of biologically effective UV approaches $70 \%$ under overcast conditions for an SZA range of $35^{\circ}-59^{\circ}$, reaching up to $84 \%$ attenuation during periods of total cover by rain-bearing pannus cloud. Large dust storms in Australia occur during periods of drought and are not normally associated with high water content clouds. However, as documented by Jin et al. (2014), cloud cover coupled with severe dust load has the potential to strongly attenuate the surface UV irradiance.

Australia experiences a high solar irradiance, due to its relatively low latitude and ozone concentrations with respect to other countries located in the Northern Hemisphere (Eyring et al. 2007). Subsequently, Australia experiences the highest incidence rates of skin cancer in the world (Leiter and Garbe 2008; AIHW 2007). Understanding the atmospheric factors that affect the surface UV irradiance contributes toward a greater awareness of the potentially harmful impacts on human health, global energy budgets, ecosystems, and the complex array of feedbacks that exist between them (U.N. Environment Programme 2014; IPCC 2014a,b,c). Given atmospheric dust levels are expected to increase as a consequence of human activity and climate variability, a better understanding of the effects of dust aerosol on the surface UV irradiance needs to be developed. In Australia, the most significant contributor of global dust load in the Southern Hemisphere, studies reporting spectral modification due to dust aerosol are limited. This is a result of the relatively low number of national UV radiation monitoring sites along the populated eastern coast and the task-specific roles of available instrumentation. The highest UV attenuation documented in Australia was reported by Kalashnikova et al. (2007). This work studied the influence of smoke and dust aerosols over Darwin $\left(12.3^{\circ} \mathrm{S}, 130.5^{\circ} \mathrm{E}\right)$ and Alice Springs $\left(23.4^{\circ} \mathrm{S}, 133.5^{\circ} \mathrm{E}\right)$. At the reported peak AOD of 0.6 , Kalashnikova et al. (2007) determined a reduction in the solar ultraviolet B (UVB, 290-315 nm) of 40\%$50 \%$, which decreased to $20 \%-25 \%$ in the ultraviolet A (UVA, 315-400 nm). Chee and Mills (2010) modeled lower surface UV attenuation using Aerosol Robotic Network (AERONET) sun photometers located in four Australian cities, with the highest attenuation being reported for a peak AOD of 0.38. McGowan and Clark (2008) measured total solar attenuation by desert dust under cloud-free conditions [confirmed 
by Moderate Resolution Imaging Spectroradiometer (MODIS) Terra satellite analysis] during the frontal passage of an Australian dust event that moved through western Queensland on 19 October 2003. During the event, peak $\mathrm{PM}_{10}$ surface concentrations (particulate matter less than $10 \mu \mathrm{m}$ ) exceeded $130 \mu \mathrm{g} \mathrm{m}^{-3}$. This concentration peak corresponded to a brief fall in the measured total solar irradiance from 984 to $409 \mathrm{~W} \mathrm{~m}^{-2}$ (41.6\% attenuation).

The motivation of the current study is to 1) document the measured spectral UV attenuation during the most severe dust event in recent Australian history, 2) use the measured spectral UV irradiance data taken during the passage of the 23 September 2009 event to characterize the UV attenuation due to the presence of cloud-plus-dust immediately preceding the arrival of the frontal system, and 3) characterize the UV attenuation after the passing of the frontal system (dust only). These measurements will allow the first comparative assessment of UV attenuation due to dust and cloud in the Northern and Southern Hemispheres.

\section{MEASUREMENT SITE AND INSTRUMEN-} TATION. UV spectral irradiance measurements have been made at the University of Southern Queensland (USQ), Toowoomba campus, since January 2003. Toowoomba is an elevated $(693 \mathrm{~m}$ above sea level), relatively unpolluted regional city located approximately $130 \mathrm{~km}$ inland of the Pacific Ocean. The clean air and high number of cloudfree days (Sabburg et al. 1997) make the site ideal for the study of dust aerosol contributions to the surface solar irradiance. The site is the location of a
Bentham Instruments scanning spectroradiometer (model DTM300, Reading, United Kingdom) and the Total Sky Imaging System [TSI, model TSI-440, Yankee Environmental Systems (YES), Turners Falls, Massachusetts]. These instruments were utilized in this study to monitor the spectral UV irradiance and sky view, respectively. USQ's Toowoomba campus measurement site is located upon a three-story rooftop so that from this elevated position both instruments have a near-hemispherical sky view. The $\mathrm{PM}_{10}$ surface aerosol loads were monitored in Toowoomba by the Queensland Government's Department of Environment and Heritage Protection (DEHP). MODIS Terra and Aqua satellite AOD measurements were used to supplement surface $\mathrm{PM}_{10}$ measurements for comparison to spectral UV scans and sky images taken over the period 16-30 September 2009.

The Bentham spectroradiometer is based around a 600-mm focal length double monochromator (model DTMc300F) utilizing a pair of holographic gratings with 2,400 lines per millimeter blazed at $250 \mathrm{~nm}$. Signal input is via a D5-H diffuser and 1-m-long fiberoptic cable. The UV sensitive detector is a side-window photomultiplier tube with a bialkali photocathode (model DH10) that employs an analog-to-digital converter (model 228A) to relay spectral irradiance to a dedicated personal computer (PC) for storage. The double-monochromator input and output slit widths are set at $0.37 \mathrm{~mm}$, giving the instrument a nominal spectral resolution of $0.5 \mathrm{~nm}$, as specified by the manufacturer. Scans take on average $3 \mathrm{~min}$ to complete and are made in 10-min intervals across the UV spectrum from 280 to $400 \mathrm{~nm}$. The spectral scans start daily at 0500 and end at 1900 Australian
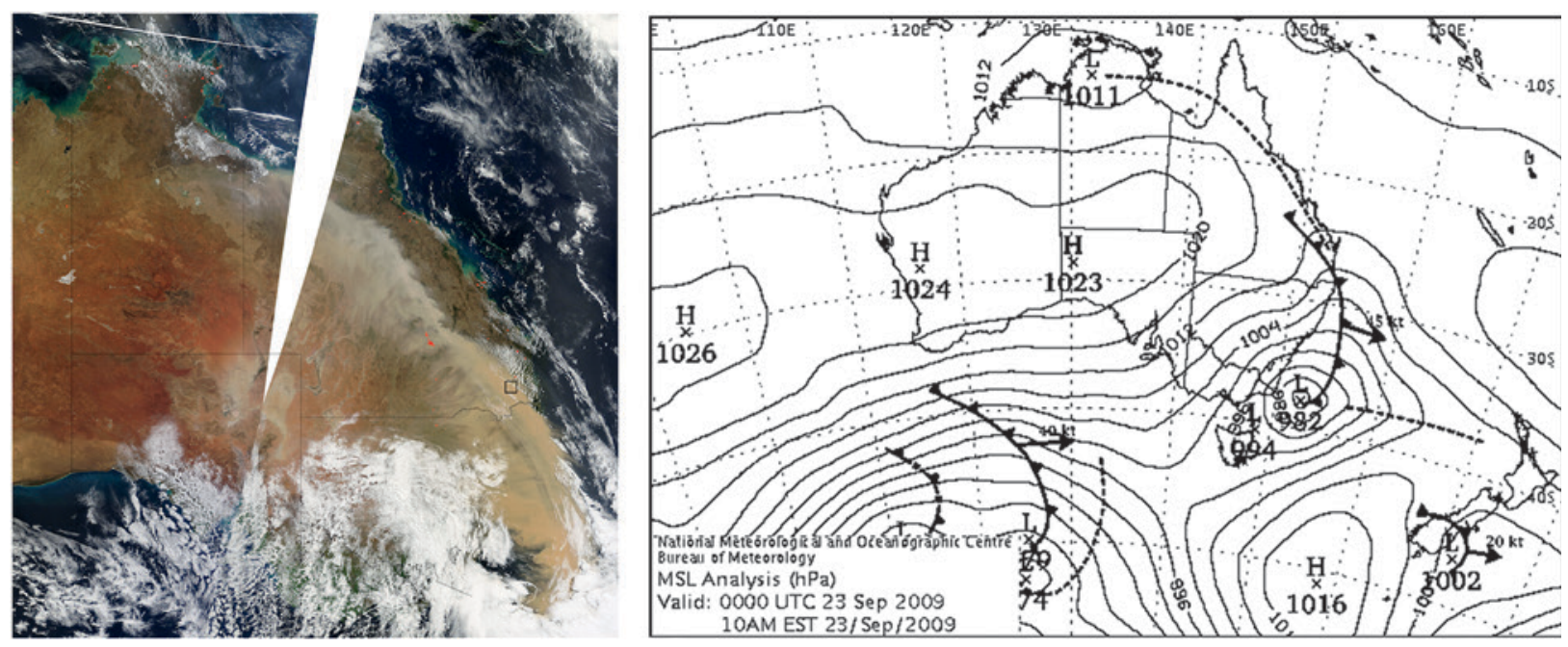

FIG. I. (left) MODIS Terra satellite image at 1005 AEST 23 Sep 2009. Toowoomba is located within the open square. (right) Australian Bureau of Meteorology synoptic chart from I000 AEST 23 Sep 2009. 
eastern standard time (AEST). The system is housed in a purpose-built air-conditioned environmentally sealed container held at a constant temperature of $25^{\circ} \pm 1^{\circ} \mathrm{C}$. Calibration to three sets of quartz tungsten halogen (QTH) lamps are performed on a monthly basis. The calibration procedure includes wavelength stability checking against the spectral lines of a mercury lamp. The total uncertainty of the instrument is rated at $\pm 9 \%$ based on temporal stability, cosine error, dark count variability, and lamp traceability to the National Physical Laboratory U.K. standard (Parisi and Downs 2004).

The TSI-440 consists of a skyward-facing hemispherical mirrored surface that is imaged by a downward-facing filtered charge-coupled device (CCD) web camera. Cloud fraction, determined as the total percentage of sky view obscured by cloud and expressed as a fraction from 0 to 1 , is measured automatically using the YES image processing algorithm (Sabburg and Long 2004). The TSI-440 installed at the USQ measurement site monitors sky
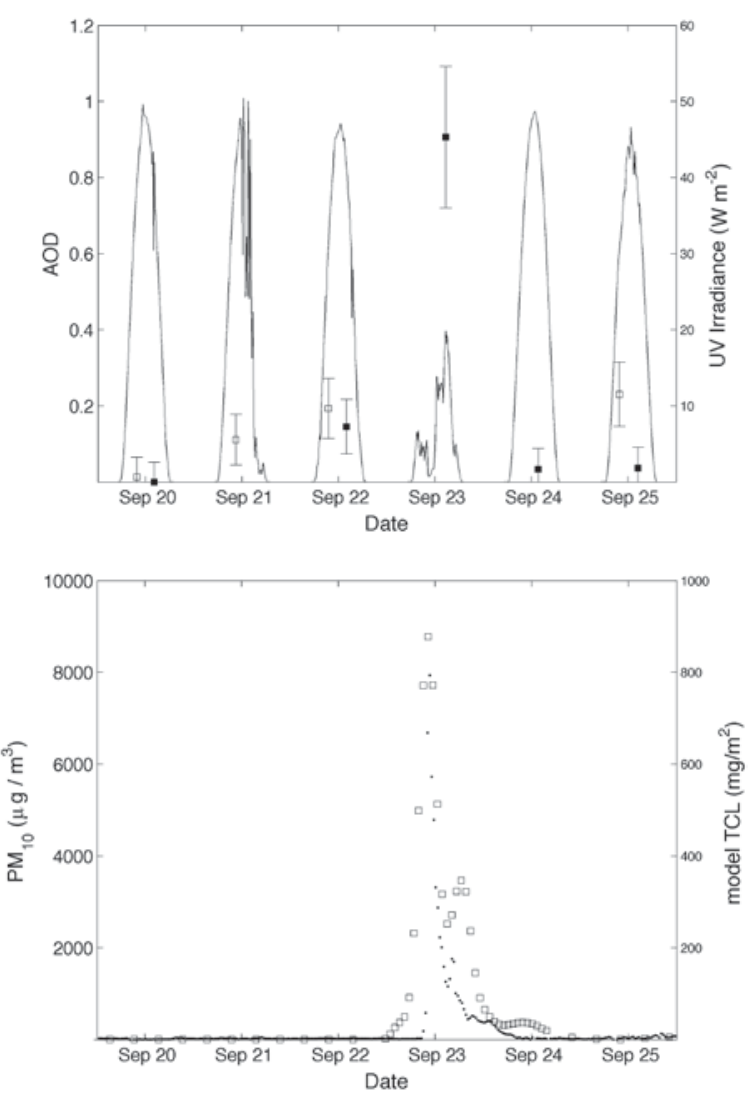

FIG. 2. (top) MODIS Terra AOD (open squares), MODIS Aqua AOD (filled squares), and measured UV irradiance for the period 20-25 Sep 2009. (bottom) DEHP 30-min average PM $_{10}$ (dots) and CEMSYS TCL (open squares) for the same time series. fraction every minute of the day in the SZA range $0^{\circ}-80^{\circ}$. Daily monitoring begins and shuts down automatically when the SZA falls within this range. The field of view analyzed by the TSI- 440 is $160^{\circ}$. This prevents analysis of low-level surface obstructions. A black $2.5-\mathrm{cm}$-wide semireflective shadow band attached to the TSI hemispherical mirror surface rotates with the mirror, depending on the solar azimuth to protect the CCD web camera sensor from saturation by direct sunlight reflections. The shadow band and web camera housing cover approximately $9.5 \%$ of the available sky view. The YES software analyzes each sky image to determine whether the sun is obscured by the passage of cloud. TSI- 440 factory settings are consistent with the World Meteorological Organization (WMO) definition of solar obstruction (Pfister et al. 2003). USQ's TSI-440 is set higher than the default factory setting so that optically thin cirrus cloud and thick aerosol hazes are counted as solar obstructions (Sabburg and Long 2004). The TSI-440 is connected via a local area network to the same PC as the Bentham spectroradiometer, ensuring data logged by both instruments carries the same time stamp. The uncertainty of the TSI- 440 automated cloud fraction is estimated at $\pm 10 \%$ for most sky-image cases (Long et al. 2001). Images of cloud (and dust) at the Toowoomba site were captured by the TSI- 440 during the period 16-25 September whereupon web camera malfunction (possibly due to the preceding dust event of 23 September) prevented image analysis until the camera was cleaned and reset to capture images on 29 September 2009.

Surface concentration of suspended $\mathrm{PM}_{10}$ was monitored using a tapered element oscillating microbalance (TEOM) operated by DEHP (DEHP 2015). These instruments sample $\mathrm{PM}_{10}$ at a height of $3 \mathrm{~m}$ above the surface. Park et al. (2009) estimated the uncertainly of $\mathrm{PM}_{10}$ TEOM samplers at $\pm 23.4 \%$. The Toowoomba TEOM (discontinued in December 2010) was installed as part of the southeast Queensland Air Quality (QAQ) monitoring network, and was located at Willowburn Oval, Toowoomba (approximately $7.5 \mathrm{~km}$ from the USQ measurement site). This instrument provided half-hourly averages of surface-level $\mathrm{PM}_{10}$ dust concentrations and was primarily employed to track the temporal concentration of dust over Toowoomba on 23 September 2009. Background $\mathrm{PM}_{10}$ aerosols were also determined using this instrument by analysis of publicly available September data for the years 2003-10. The $\mathrm{PM}_{10}$ dust fraction accounted for approximately $68 \%$ of the sampled 23 September particulate mass (Jayaratne et al. 2011). The DEHP PM ${ }_{10}$ TEOM data are therefore considered 
a reasonable surrogate measure for total column dust load (TCL). These measurements were however complemented by the use of 1) the Computational Environmental Management System (CEMSYS) wind erosion and dust transport model (Leys et al. 2010; Butler et al. 2011); and 2) MODIS satellite measurements of the AOD. CEMSYS performance has been tested against national DustWatch and QAQ network $\mathrm{PM}_{10}$ air sampling station measurements and is primarily employed to model dust transport on a national scale at $50-$ and $10-\mathrm{km}$ resolutions. CEMSYS was used in this research to track the progression of the 23 September event independently of surface $\mathrm{PM}_{10}$ measurements.

AOD measurements retrieved from MODIS on board the National Aeronautics and Space Administration (NASA) Earth Observing System (EOS) Terra and Aqua satellites (NASA 2015a) were used to further supplement local halfhourly surface $\mathrm{PM}_{10}$ measurements during the September 2009 study period. These satellites provide two daily AOD sampling opportunities at approximately 0930 and 1400 AEST, respectively. Geolocated swaths for corrected optical depth at $470 \mathrm{~nm}$ over land were analyzed from the MYD04 L2 (Aqua) and MOD04_L2 (Terra) data products. Where available, the AOD for the nearest $10 \mathrm{~km} \times 10 \mathrm{~km}$ pixel matching the Toowoomba measurement site's latitude and longitude were extracted twice daily between 16 and 30 September 2009. The MODIScorrected AOD has a documented accuracy of $\pm(0.05+0.15$ AOD) (Remer et al. 2005).

\section{AEROSOL SOURCE REGIONS AND SYNOPTIC CONDI-} TIONS. Dust storm events in Australia are frequently characterized by entrainment in the Lake Eyre basin, central Australia. This is the most common region in Australia for dust entrainment, with peak seasonal activity occurring in the austral spring and early summer
(September-December) preceding flooding by river systems that drain into the basin following summer rains (Strong et al. 2011). Entrainment in these regions is often associated with the progression of frontal systems. These frontal systems are characterized by dry prefrontal northerlies, which are followed

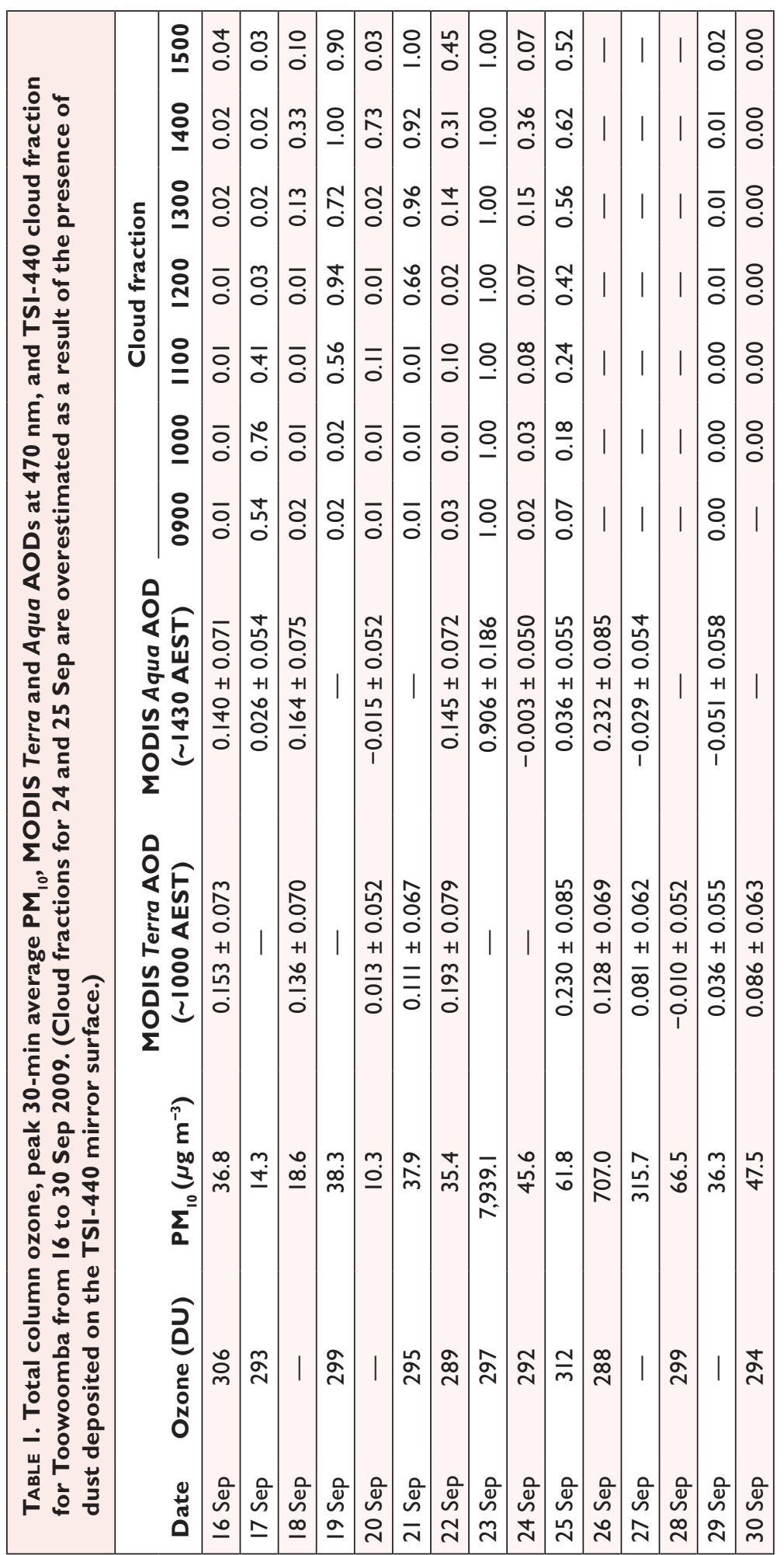



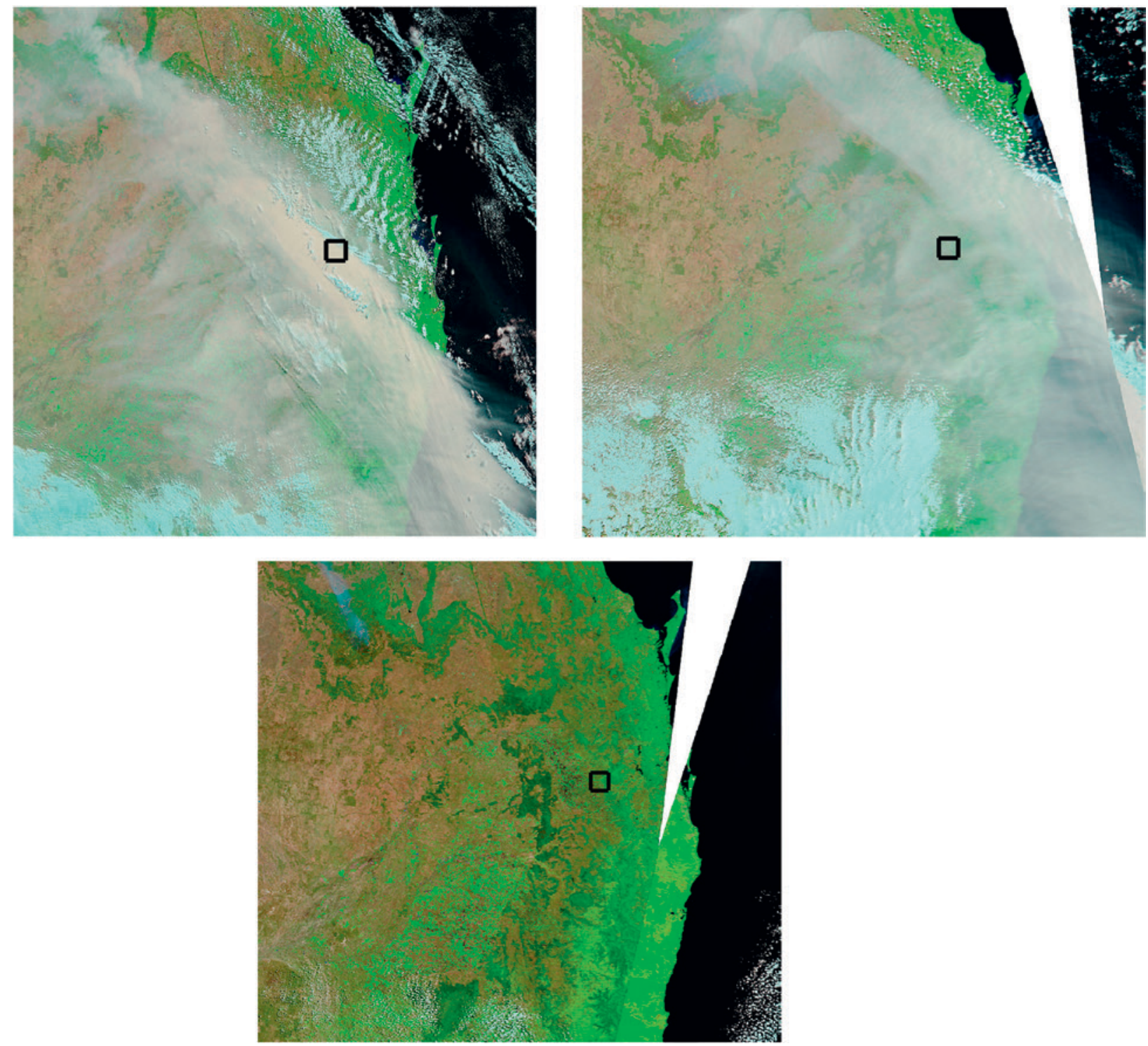

FIG. 3. MODIS 7-2-I images. Location of Toowoomba is shown by an open square. (top left) Morning and (top right) afternoon of 23 Sep 2009, and (bottom) morning of 24 Sep 2009.

by southerly postfrontal or frontal westerly winds (Strong et al. 2011). The arrival of sediment into the Lake Eyre basin during the 2008-09 wet season, along with dry weather preceding the 2009 dust season, contributed significantly to increased sediment availability within the arid and semiarid regions of central Australia. These regions included the lower Lake Eyre basin, grazing and mining areas of northwestern New South Wales, and the Channel Country of western Queensland, some 800-1,200 km from the Toowoomba measurement site (Leys et al. 2011).

During the period 22-23 September 2009, a cold front and prefrontal trough passed over the dust source regions as winds shifted from northwesterly to southwesterly and a low pressure system intensified behind the front over southeastern Australia. Wind speeds behind the front reached significant force, entraining the dust that passed over the Australian coastline on 23 September 2009 (Leys et al. 2011). During the passage of the 23 September frontal system, dust-affected surface stations reported a significant fall in humidity accompanied by the arrival of the dust plume (Jones and Christopher 2011). In addition, these stations also reported a brief temperature increase followed by a later fall (Jones and Christopher 2011). Jones and Christopher (2011) attribute the brief rise in temperature to the convergence of warm air ahead of the surface front and the fall to southerly cold-air advection. These observations favor the development of cloud ahead of the 
front, followed by cooler stable conditions as drier dust-laden air falls in behind the frontal system. The presence of cloud ahead of the front and the absence of cloud behind were confirmed by MODIS satellite images. Unlike the high-altitude NAH-A Saharan dust events, the sinking cool air associated with the frontal dust plume of 23 September contributed to lower vertical dust profiles. A significant proportion of the 23 September dust plume was identified below $1 \mathrm{~km}$ at Toowoomba's latitude (Jones and Christopher 2011).

A comparison of the MODIS Terra true-color satellite image is made with the synoptic chart of 1000 AEST 23 September 2009 issued by the Australian Bureau of Meteorology in Fig. 1. The extent of the dust plume during the 23 September event is clear and can be seen to extend along a wide latitudinal gradient behind the cold front (southeastern coastline) and prefrontal trough (northeastern coastline), which is depicted on the synoptic chart. For the situation illustrated in Fig. 1, the front has already passed through Sydney, lying eastward of the New South Wales coast, and is approaching Brisbane farther to the north. The Toowoomba measurement site, west of Brisbane, is highlighted in Fig. 1 (left).

RESULTS AND DISCUSSION. Dust aerosol, cloud, and UV irradiance time series. The measured UV irradiance and MODIS AOD for the period 20-25 September is shown in Fig. 2 relative to surface $\mathrm{PM}_{10}$ and CEMSYS-modeled TCL. The highest recorded dust aerosol concentrations during the 14-day period (16-30 September 2009) were measured on 23 September. During 23 September, the $\mathrm{PM}_{10}$ concentration peak of 7,939.1 $\mathrm{g} \mathrm{m}^{-3}$ occurred at 1030 AEST, while the modeled TCL peak of $878 \mathrm{mg} \mathrm{m}^{-2}$ occurred at 1000 AEST. These peaks correlate well with the minimum recorded UV irradiance at 0950 AEST. This minimum corresponds to the period immediately following the arrival of the front over the Toowoomba observation site at 0930 AEST. During this period, the $\mathrm{PM}_{10}$ concentration remained above $1,000 \mu \mathrm{g} \mathrm{m}^{-3}$. These results are significantly high when compared to those of the following day (24 September), which averaged a $\mathrm{PM}_{10}$ concentration of $43.4 \mu \mathrm{g} \mathrm{m}^{-3}$ from 0500 to 1900 AEST (Table 1).

TSI-440 cloud fraction, peak $\mathrm{PM}_{10}$, MODIS Terra and Aqua AOD, and daily Ozone Monitoring Instrument (OMI) total column ozone (National Oceanic and Atmospheric Administration 2014) are listed in Table 1 for the 7 days preceding and following 23 September 2009. The OMI ozone measurements are in Dobson units (DU) and represent the
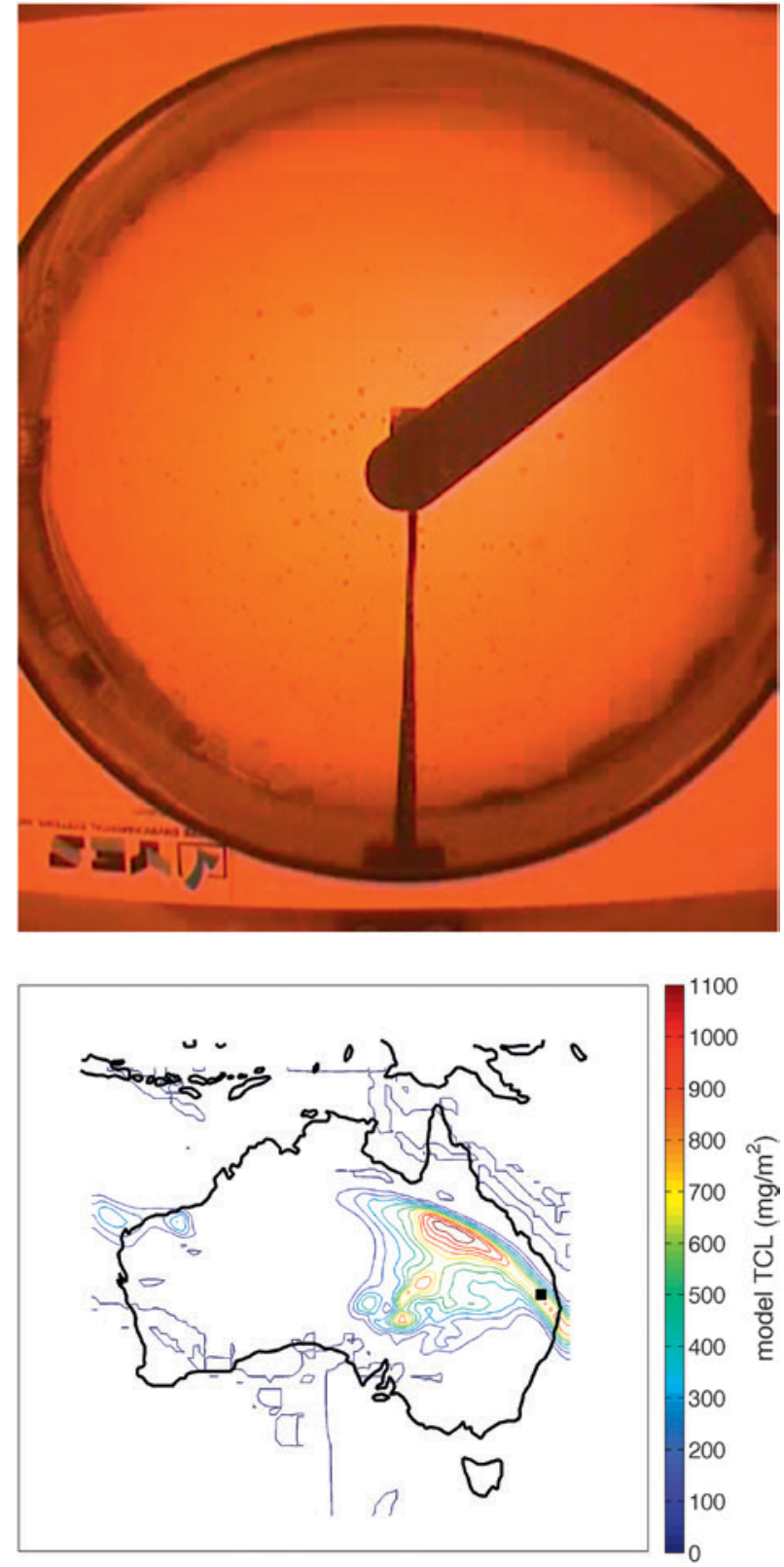

Fig. 4. (top) Whole-sky image at 0950 AEST 23 Sep 2009 and (bottom) CEMSYS model TCL for the same date and time. Toowoomba is marked as a solid square.

satellite measurement of ozone through the entire atmospheric column. Cloud fractions determined from the TSI-440 images are listed in Table 1 for images captured at the beginning of each hourly period from 0900 to 1500 AEST. Reddening of TSI-440 sky images clearly shows the influence of dust during the daylight hours of 23 September. This resulted in overcast cloud fractions (1.0) being recorded from 0652 AEST to the end of daily image collection at 1659 AEST 23 September. Although corrected AODs from MODIS Terra were not available at this time for the 

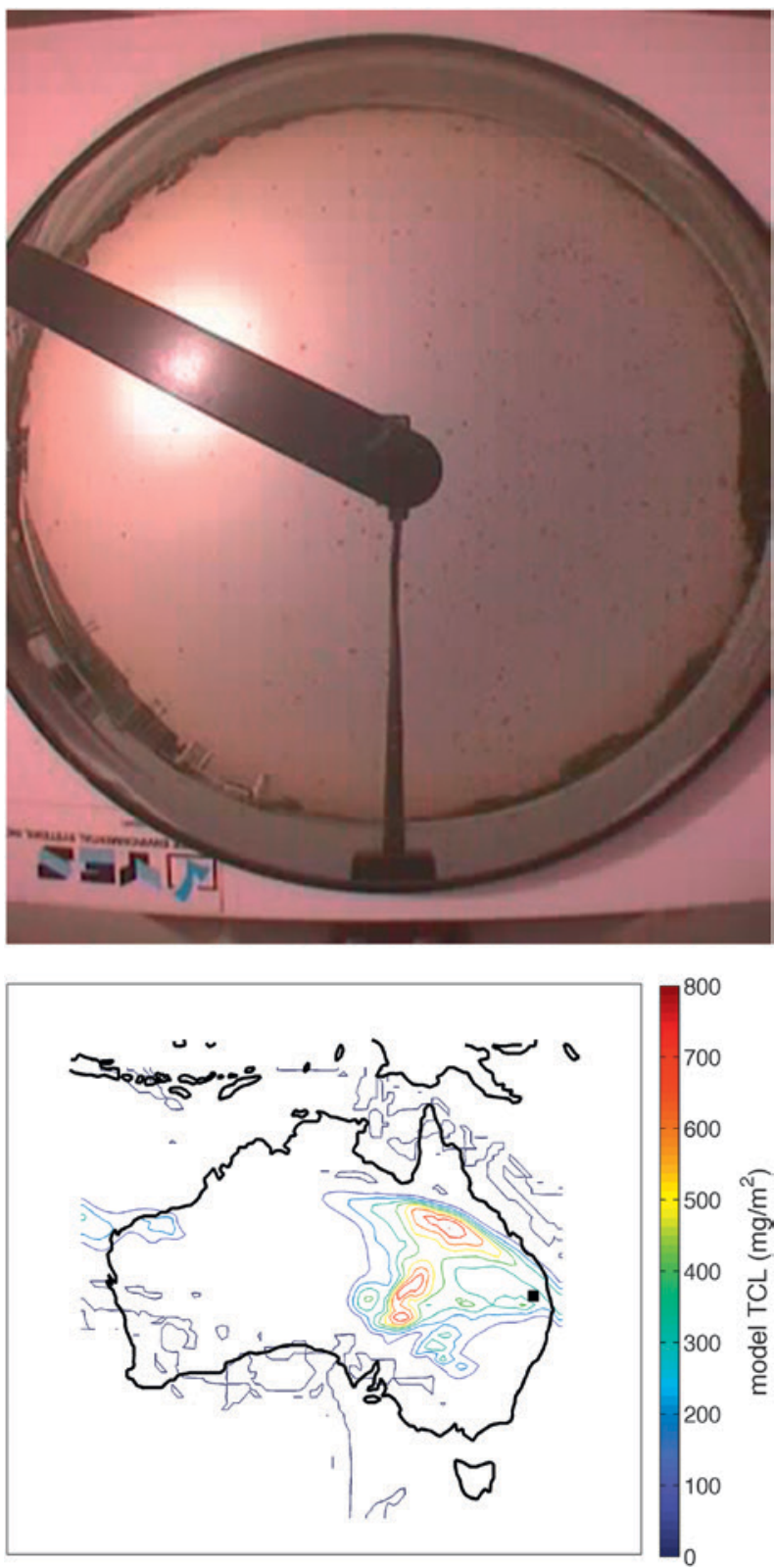

Fig. 5. (top) Whole-sky image at I430 AEST 23 Sep 2009 and (bottom) CEMSYS model TCL for the same date and time. Toowoomba is marked as a solid square.

Toowoomba observation site, an AOD of $1.130 \pm 0.220$ was measured approximately $70 \mathrm{~km}$ to the east at 1005 AEST. At 1425 AEST 23 September, MODIS Aqua recorded an AOD of $0.906 \pm 0.186$ for the Toowoomba observation site, which is the peak daily AOD listed in Table 1 and shown in Fig. 2.

Cloud-free days were observed over the study site on 16, 24, 29, and 30 September. Of the available cloud-free days, 24 September was selected for comparison of the spectral UV irradiance (and associated dependence) of dust aerosol. Correction factors were determined to account for the difference in total column ozone between 24 September (292 DU) and 23 September (297 DU). Interpolation of correction factors calculated for the cloud-free days at different total column ozone concentrations to the 24 September cloud-free spectra resulted in comparable (reduced) cloud-free UV irradiance estimates for 23 September 2009 (see the next section, "Modification of the Clear-Sky UV Irradiance"). Spectral UV irradiance comparisons were determined for wavelengths, $\lambda$, in the range $296-400 \mathrm{~nm}$, and expressed as a dust modification ratio (DMR):

$$
\operatorname{DMR}(\lambda)=\frac{\operatorname{UV}_{d}(\lambda)}{\operatorname{UV}_{0}(\lambda)},
$$

where $\mathrm{UV}_{d}$ is the dust-affected irradiance and $\mathrm{UV}_{0}$ is the cloud- and dust-free irradiance modified from spectral irradiance measurements taken on 24 September 2009.

High dust aerosol and the presence of prefrontal cloud on the morning of 23 September were significant contributing factors affecting the observed UV attenuation evident in the Toowoomba data. Two DMR cases were therefore considered during the passing dust event. These included measurements taken during maximum UV attenuation at 0950 AEST (case 1) and UV attenuation due to dust aerosol at 1430 AEST (case 2). Case 1 represents attenuation due to the combined influence of dust aerosol plus cloud being measured immediately after the arrival of the prefrontal trough. Case 2 was confirmed as cloud free by MODIS satellite imagery and the TSI-440 sky camera.

Figure 3 compares composite 7-2-1 MODIS satellite images (NASA 2015b) taken on the morning of 23 September (1000 and 1005 AEST), the afternoon of 23 September $(1245,1250$, and 1425 AEST), and during the cloud-free low aerosol reference day of 24 September (1040 and 1045 AEST). The false color 7-2-1 images show cloud as white to blue and vegetated regions in bright green. Smoke aerosol emanating from fires visible to the northwest of the Toowoomba observation site are unlikely to have contributed to the measured aerosol load of 23 September, with the visible smoke plume seen extending eastward and well above Toowoomba's latitude. As seen in the 7-2-1 frame comparison, no cloud is present in the vicinity of the Toowoomba observation site in the afternoon MODIS image of 23 September (Fig. 3, top right). This image corresponds with the afternoon MODIS Aqua AOD measurement (Table 1), a period during which the surface $\mathrm{PM}_{10}$ had fallen from its morning peak of 7,939.1 to $1,260.4 \mu \mathrm{g} \mathrm{m}^{-3}$. Comparison of the Toowoomba observation site TSI-440 sky view and modeled TCL confirms the significant reduction in 
dust aerosol load by midafternoon (Figs. 4 and 5). An animated image series for the entire 23 September 2009 event is included in the article supplement (http://dx.doi.org/I0.II75/BAMS-D-I5-00053.2).

Modification of the clear-sky UV irradiance. The greatest attenuation in the global UV irradiance due to dust aerosol and clouds together was observed between 0930 and 1150 AEST on 23 September. This period corresponds to the arrival of dust over the irradiance input optic at 0930 AEST coupled with overlying lowlevel cloud cover. After 1150 AEST the TSI recorded no further obstruction by cloud for the subsequent UV irradiance measurements performed in 10-min intervals up to 1900 AEST. Figure 6 compares the measured DMR for 23 September to the corrected cloud-free irradiance of 24 September at 0950 and 1430 AEST. A strong reduction of the UV irradiance is evident in Fig. 6 during maximum attenuation by cloud and dust over the measurement site at 0950 AEST. The maximum DMR at this time reached 0.005. This corresponded to attenuation of the UVB of between $99.5 \%$ at $297 \mathrm{~nm}$ and $98.6 \%$ at $300 \mathrm{~nm}$. In the UVA, attenuation decreased slightly, ranging between $99.0 \%$ at $315 \mathrm{~nm}$ and $97.6 \%$ at $400 \mathrm{~nm}$. The presence of cloud, which most likely attributed to the upward transport of warm humid air ahead of the arrival of the cold front, is a significant contributing factor to the observed attenuation. Combined with the presence of dust aerosol at low altitudes, these recordings support the high UV reductions observed by Jin et al. (2014) over Tazhong, China. The maximum UV irradiance recorded during the Jin et al. (2014) study of the dust-plus-cloud event was approximately $10 \mathrm{~W} \mathrm{~m}^{-2}$; in contrast, during the 23 September 2009 event, the UV irradiance recorded during the peak dust load was $0.7 \mathrm{~W} \mathrm{~m}^{-2}$. This observation indicates that the rapid passage of cloud and dust associated with the arrival of a frontal system can reduce the UV irradiance significantly further than reported by Jin et al. (2014) (Fig. 2).

The consistent synoptic conditions observed independently along the front at several ground stations show a clear fall in humidity due to cold-air advection following the passage of the frontal system (Jones and Christopher 2011). These conditions are not consistent with cloud formation. The TSI-440 measurements and the afternoon MODIS Aqua satellite imagery confirm no cloud over the Toowoomba observation site during the afternoon. Hence, any UV attenuation measured during the afternoon of 23 September can be exclusively associated with the presence of dust. Furthermore, the afternoon UV attenuation can be compared with the UV attenuation reported for the

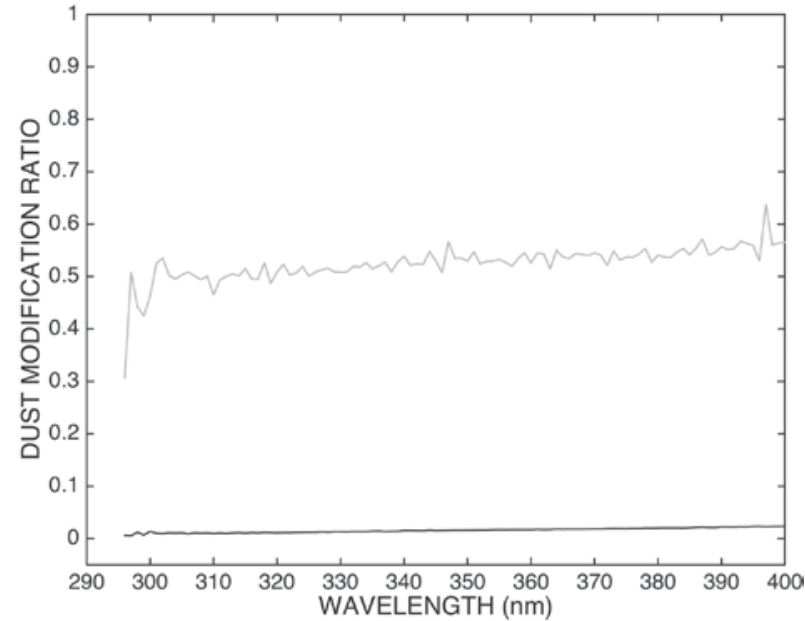

FIG. 6. DMR during maximum attenuation by cloud and dust aerosol at 0950 AEST (dark solid line) and during attenuation by dust aerosol at I430 AEST (gray line).

Saharan dust events studied by Antón et al. (2012) at El Arenosillo, Spain; Román et al. (2013) at Granada, Spain; and di Sarra et al. (2002) at Lampedusa, in the southern Mediterranean. These studies report maximum attenuation of the UV irradiance of between 30\% and $60 \%$ in the SZA range of $20^{\circ}-60^{\circ}$.

Attenuation of the UV irradiance measured at $43^{\circ}$ SZA on 23 September 2009 resulted in an approximate DMR of 0.5. Corresponding UVB attenuation ranged from $69.3 \%$ at $296 \mathrm{~nm}$ to $46.5 \%$ at $302 \mathrm{~nm}$, with the UVA attenuation ranging from $51.3 \%$ at $319 \mathrm{~nm}$ to $36.2 \%$ at $397 \mathrm{~nm}$. All dust-affected spectra displayed an increase in DMR with increasing wavelength from 300 to $400 \mathrm{~nm}$. During the period of dust attenuation from 0940 to 1530 AEST (SZA range $60^{\circ}-28^{\circ}$ ), DMR displayed positive linear gradients in the range $0.1-1.1 \times 10^{-3} \mathrm{~nm}^{-1}$ between the cloud-plus-dust and dust-affected spectra. Given the likely absence of cloud during the spectral measurements made in the afternoon, the higher observed gradients with increasing UV wavelength may be associated with dust aerosol only. Similar trends have previously been reported under extreme Saharan dust loads by di Sarra et al. (2002) and Antón et al. (2012) in the absence of cloud. However, given the coastal location of the Saharan study sites, contributions due to mixing with marine aerosols cannot be excluded as a factor in any direct comparison. The data presented in our research provide a new perspective on possible attenuation exclusively due to dust aerosols of continental origin.

CONCLUSIONS. Extreme dust conditions associated with the record-breaking dust event of 23 
September 2009 caused almost a total block out of the UV irradiance in eastern Australia. The largest UV attenuation (UVB $99.5 \%$ at $297 \mathrm{~nm}$ and $98.6 \%$ at $300 \mathrm{~nm}$; UVA $99.0 \%$ at $315 \mathrm{~nm}$ and $97.6 \%$ at $400 \mathrm{~nm}$ ) observed during the 23 September event corresponded to the arrival of the frontal system and the peak dust load (cloud-plus-dust). This was associated with favorable conditions for cloud and dust cover. These are some of the highest UVA and UVB attenuations reported in the literature to date. After the passage of the frontal system, any cloud cover dissipated as a result of the passage of drier dust-laden air following the front. As a result, the afternoon of 23 September was cloud free. Hence, the afternoon UV attenuation of greater than $50 \%$ at 1430 AEST was purely due to dust. These UV attenuations are the highest recorded aerosol modifications in Australia, being greater than previously reported UVB attenuations under smoky tropical Australian conditions of $40 \%-50 \%$ (Kalashnikova et al. 2007). That the surface UV irradiance is directly and significantly affected by dust warrants continued research, as affected UV wavelengths contribute to biologically effective radiation, the UV index, and global surface energy budgets.

ACKNOWLEDGMENTS. The authors acknowledge the Queensland Government Department of Environment and Heritage Protection for making the Willowbank Oval Air Quality network $\mathrm{PM}_{10}$ data available. We would also like to acknowledge the MODIS Land Rapid Response Team, NASA GSFC, the Australian Bureau of Meteorology, and the University of Southern Queensland.

\section{REFERENCES}

Antón, M., M. Sorribas, Y. Bennouna, J. Vilaplana, V. Cachorro, J. Gröbner, and L. Alados-Arboledas, 2012: Effects of an extreme desert dust event on the spectral ultraviolet irradiance at El Arenosillo (Spain). J. Geophys. Res., 117, D03205, doi:10.1029/2011JD016645.

AIHW, 2007: Cancer in Australia: An overview, 2006. Australian Institute of Health and Welfare Cancer Series, No. 32, 132 pp. [Avaliable online at www.aihw.gov.au/WorkArea/DownloadAsset .aspx?id=6442454559.]

Australian Radiation and Nuclear Safety Authority, 2015: Realtime UV levels. Accessed 15 December 2015. [Available online at www.arpansa.gov.au /uvindex/realtime/index.cfm.]

Butler, H., J. Leys, Y. Shao, C. Strong, and G. McTainsh, 2011: Caring for our country: Wind Erosion Extent and Severity Maps for Australia (WEESMap). University of Southern Queensland Project A0000007341, 68 pp. [Available online at https://eprints.usq.edu .au/25753/7/Butler_\%20Leys_Strong_McTainsh _CfoC_2013_AV.pdf.]

Chan, Y.-C., G. McTainsh, J. Leys, H. McGowan, and K. Tews, 2005: Influence of the 23 October 2002 dust storm on the air quality of four Australian cities. Water Air Soil Pollut., 164, 329-348, doi:10.1007 /s11270-005-4009-0.

Chee, C., and F. Mills, 2010: An initial assessment of the impact of Australian aerosols on surface ultraviolet radiation and implications for human health. IOP Conf. Ser.: Earth Environ. Sci., 11, 012019, doi:10.1088/1755-1315/11/1/012019.

DEHP, 2015: Air quality. Department of Environment and Heritage Protection, Queensland Government, accessed 12 December 2014. [Available online at www.qld.gov.au/environment/pollution /monitoring/air/.]

di Sarra, A., and Coauthors, 2002: Effects of desert dust and ozone on the ultraviolet irradiance at the Mediterranean island of Lampedusa during PAUR II. J. Geophys. Res., 107, 8135, doi:10.1029/2000JD000139.

Dunion, J., and C. Velden, 2004: The impact of the Saharan air layer on Atlantic tropical cyclone activity. Bull. Amer. Meteor. Soc., 85, 353-365, doi:10.1175 /BAMS-85-3-353.

Escudero, M., and Coauthors, 2005: Wet and dry African dust episodes over eastern Spain. J. Geophys. Res., 110, D18S08, doi:10.1029/2004JD004731.

Eyring, V., and Coauthors, 2007: Multimodal projections of stratospheric ozone in the 21st century. J. Geophys. Res., 112, D16303, doi:10.1029/2006JD008332.

Gabric, A., R. Cropp, G. McTainsh, H. Butler, B. Johnston, T. O’Loingsigh, and D. Van Tran, 2015: Tasman Sea biological response to dust storm events during the austral spring of 2009. Mar. Freshwater Res., 67, 1090-1102, doi:10.1071/MF14321.

Husar, R., and Coauthors, 2001: Asian dust events of April 1998. J. Geophys. Res., 106, 18317-18330, doi:10.1029/2000JD900788.

IPCC, 2014a: Climate Change 2014: Impacts, Adaptation, and Vulnerability. Part A: Global and Sectoral Aspects. Cambridge University Press, 1132 pp. [Available online at www.ipcc.ch/pdf/assessment -report/ar5/wg2/WGIIAR5-PartA_FINAL.pdf.]

- 2014b: Climate Change 2014: Impacts, Adaptation, and Vulnerability. Part B: Regional Aspects. Cambridge University Press, 688 pp. [Available online at www.ipcc.ch/pdf/assessment-report/ar5/wg2 /WGIIAR5-PartB_FINAL.pdf.]

- , 2014c: Climate Change 2014: Mitigation of Climate Change. Cambridge University Press, 1465 pp. 
[Available online at www.ipcc.ch/pdf/assessment -report/ar5/wg3/ipcc_wg3_ar5_full.pdf.]

Jayaratne, E., G. Johnson, P. McGarry, H. Cheung, and L. Morawska, 2011: Characteristics of airborne ultrafine and coarse particles during the Australian dust storm of 23 September 2009. Atmos. Environ., 45, 3996-4001, doi:10.1016/j.atmosenv.2011.04.059.

Jin, L., Q. He, Z. Li, R. Liu, A. Mamtimin, and Q. Miao, 2014: Characteristics of UV radiation at Tazhong of the Tarim Basin, west China. Meteor. Atmos. Phys., 126, 91-103, doi:10.1007/s00703-014-0337-1.

Jones, T., and S. Christopher, 2011: Assessment of temperature and humidity changes associated with the September 2009 dust storm in Australia. IEEE Geosci. Remote Sci., 8, 268-272, doi:10.1109 /LGRS.2010.2063693.

Kalashnikova, O., F. Mills, A. Eldering, and D. Anderson, 2007: Application of satellite and ground-based data to investigate the UV radiative effects of Australian aerosols. Remote Sens. Environ., 107, 65-80, doi:10.1016/j.rse.2006.07.025.

Kuchinke, C., and M. Nunez, 1999: Cloud transmission estimates of UV-B erythemal irradiance. Theor. Appl. Climatol., 63, 149-161, doi:10.1007/s007040050100.

Leiter, U., and C. Garbe, 2008: Epidemiology of melanoma and nonmelanoma skin cancer-The role of sunlight. Adv. Exp. Med. Biol., 624, 89-103, doi:10.1007/978-0-387-77574-6_8.

Leys, J., H. Butler, X. Yang, and S. Heidenreich, 2010: CEMSYS modelled wind erosion. PRN 08081220, Dept. of Environment, Climate Change and Water, NSW Government, 85 pp. [Available online at www.environment.nsw.gov.au/resources /soils/10321cemsyswind.pdf.]

- , S. Heidenreich, C. Strong, G. McTainsh, and S. Quigley, 2011: $\mathrm{PM}_{10}$ concentrations and mass transport during 'Red Dawn' - Sydney 23 September 2009. Aeolian Res., 3, 327-342, doi:10.1016/j .aeolia.2011.06.003.

Long, C., D. Slater, and T. Tooman, 2001: Total Sky Imager (TSI) model 880 status and testing results. Atmospheric Radiation Measurement Program Tech. Rep. ARM TR-006, Office of Energy Research, Office of Health and Environmental Research, U.S. Department of Energy, 17 pp. + appendixes. [Available online at www .arm.gov/publications/tech_reports/arm-tr-006.pdf.]

McGowan, H., and A. Clark, 2008: A vertical profile of PM10 dust concentrations measured during a regional dust event identified by MODIS Terra, western Queensland, Australia. J. Geophys. Res., 113, F02S03, doi:10.1029/2007JF000765.

— , and J. Soderholm, 2012: Laser ceilometer measurements of Australian dust storm highlight the need for reassessment of atmospheric dust plume loads. Geophys. Res. Lett., 39, L02804, doi:10.1029/2011GL050319.

McTainsh, G., Y.-C. Chan, H. McGowan, J. Leys, and K. Tews, 2005: The 23rd October 2002 dust storm in eastern Australia: Characteristics and meteorological conditions. Atmos. Environ., 39, 1227-1236, doi:10.1016/j.atmosenv.2004.10.016.

Meloni, D., A. di Sarra, T. D. Iorio, and G. Fiocco, 2004: Direct radiative forcing of Saharan dust in the Mediterranean from measurements at Lampedusa Island and MISR space-borne observations. J. Geophys. Res., 109, D08206, doi:10.1029/2003JD003960.

NASA, 2015a: LAADS Web: Level 1 and Atmosphere Archive and Distribution System. NASA Goddard Space Flight Center, Accessed 18 December 2015. [Available online at https://ladsweb.nascom.nasa .gov/data/search.html.]

_- 2015b: LANCE-MODIS. NASA Goddard Space Flight Center, Accessed 18 December 2015. [Available online at http://lance-modis.eosdis.nasa.gov /imagery/.]

National Oceanic and Atmospheric Administration, 2014: Earth System Research Laboratory OMI time series ozone data. NOAA/ESRL, Accessed 11 November 2014. [Available online at www.esrl.noaa .gov/gmd/grad/neubrew/OmiDataTimeSeries.jsp.]

Parisi, A., and N. Downs, 2004: Cloud cover and horizontal plane eye damaging solar UV exposures. Int. J. Biometeor., 49, 130-136, doi:10.1007/s00484-004 -0213-7.

Park, J.-M., J. Rock, L. Wang, Y.-C. Seo, A. Bhatnagar, and S. Kim, 2009: Performance evaluation of six different aerosol samplers in a particulate matter generation chamber. Atmos. Environ., 43, 280-289, doi:10.1016/j.atmosenv.2008.09.028.

Pfister, G., R. McKenzie, J. Liley, A. Thomas, B. Forgan, and C. Long, 2003: Cloud coverage based on all-sky imaging and its impact on surface solar irradiance. J. Appl. Meteor., 42, 1421-1434, doi:10.1175/1520 -0450(2003)042<1421:CCBOAI >2.0.CO;2.

Prospero, J., 1999: Long-term measurements of the transport of African mineral dust to the southeastern United States: Implications for regional air quality. J. Geophys. Res., 104, 15 917-15 927, doi:10.1029/1999JD900072.

Remer, L., and Coauthors, 2005: The MODIS aerosol algorithm, products and validation. J. Atmos. Sci., 62, 947-973, doi:10.1175/JAS3385.1.

Román, R., and Coauthors, 2013: Evaluation of the desert dust effects on global, direct and diffuse spectral ultraviolet irradiance. Tellus, 65B, 19578, doi:10.3402/tellusb.v65i0.19578. 
Sabburg, J., and C. Long, 2004: Improved sky imaging for studies of enhanced UV irradiance. Atmos. Chem. Phys., 4, 2543-2552, doi:10.5194/acp-4-2543-2004.

_- A. Parisi, and J. Wong, 1997: Ozone, cloud, solar and UV-B levels at a low pollution, Southern Hemisphere, sub-tropical site for winter/spring 1995. Australas. Phys. Eng. Sci. Med., 20, 198-202.

Strong, C., K. Parsons, G. McTainsh, and A. Sheehan, 2011: Dust transporting wind systems in the lower Lake Eyre Basin, Australia: A preliminary study. Aeolian Res., 2, 205-214, doi:10.1016/j.aeolia.2010.11.001.

Toledano, C., V. Cachorro, A. de Frutos, M. Sorribas, N. Prats, and B. de la Morena, 2007: Inventory of African desert dust events over the southwestern Iberian Peninsula in 2000-2005 with an AERONET Cimel Sun photometer. J. Geophys. Res., 112, D21201, doi:10.1029/2006JD008307.
Tozer, P., and J. Leys, 2013: Dust storms-What do they really cost? Rangeland J., 35, 131-142, doi:10.1071 /RJ12085.

UNEP, 2014: Environmental effects of ozone depletion and its interactions with climate change: 2014 assessment. U.N. Environment Programme, 236 pp. [Available online at http://ozone.unep.org/Assessment _Panels/EEAP/eeap_report_2014.pdf.]

VanCuren, R., and T. Cahill, 2002: Asian aerosols in North America: Frequency and concentration of fine dust. J. Geophys. Res., 107, 4804, doi:10.1029/2002JD002204.

Yin, X., Y. Ren, X. M. W. Li, D. Xu, and Z. Yang, 2013: A potential vorticity analysis on the occurrence mechanism of a strong sandstorm in northern China on April 28-29, 2011. J. Desert Res., 33, 195-204, doi:10.7522/j.issn.1000-694X.2013.00028.

\section{NEW FROM AMS BOOKS!}

\section{The Thinking Person's Guide to Climate Change}

\section{Robert Henson}

Expanded and updated from Henson's Rough Guide to Climate Change, 3rd edition (no longer in print), combining years of data with recent research, including conclusions from the Fifth Assessment Report of the Intergovernmental Panel on Climate Change, the Guide breaks down the issues into straightforward categories:

$>\quad$ Symptoms, including melting ice and extreme weather

$>$ Science, laying out what we know and how we know it

$>\quad$ Debates, tackling the controversy and politics

$>$ Solutions and Actions for creating the best possible future

(C) 2014, 516 pages, paperback ISBN: 978-1-878220-73-7

List price: $\$ 30$ AMS Member price: $\$ 20$

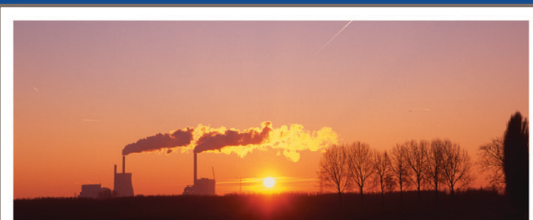

THE THINKING PERSON'S GUIDE TO CLIMATE CHANGE ROBERT HENSON

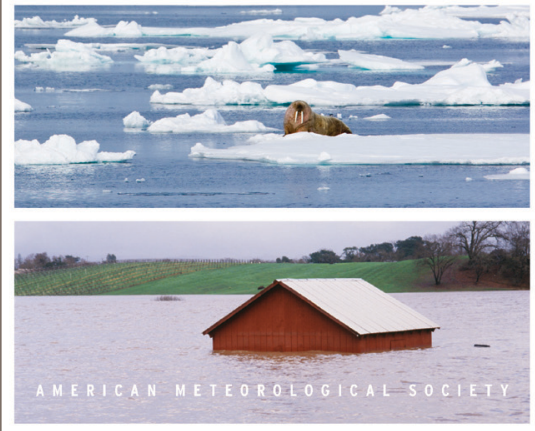
\begin{tabular}{l}
\hline \\
\hline
\end{tabular} 